\title{
Oportuzumab Monatox
}

National Cancer Institute

\section{Source}

National Cancer Institute. Oportuzumab Monatox. NCI Thesaurus. Code C61307.

A fusion protein immunotoxin consisting of a humanized, single-chain monoclonal antibody fragment specific for the epithelial cell adhesion molecule (EpCAM) conjug ated with a truncated form of Pseudomonas exotoxin A with potential antineoplastic activity. Oportuzumab monatox binds to Ep-CAM-positive tumor cells, thereby delivering the Pseudomonas exotoxin A moiety specifically; the Pseudomonas exotoxin A moiety then inactivates elongation factor 2 (EF-2) through ADP ribosylation, resulting in inhibition of protein synthesis in target cells. EpCAM, a cell surface protein, is expressed by a variety of tumor cells and is frequently found in head and neck cancers. 